\title{
Spawning pattern of the Japanese sardine Sardinops melanostictus off southern Kyushu and Shikoku, southwestern Japan
}

\author{
Ichiro Aoki, Tsukasa Murayama \\ Ocean Research Institute, University of Tokyo, Nakano, Tokyo 164, Japan
}

\begin{abstract}
Distribution, maturation and spawning of Japanese sardine Sardinops melanostictus in relation to the Kuroshio current are reported from an investigation off southern Kyushu and Shikoku, southwestern Japan, during the 1991 spawning season. Data were obtained from hydroacoustic surveys, measurement of gonadosomatic index and histological examination of oocyte maturity stage. Sardine shoals were distributed in both the coastal and the Kuroshio regions, but the maturity data showed a difference in spawning activity between the regions. Spawning activity was higher in the Kuroshio region than in the inshore region. Spawning was concentrated within a short period of about $10 \mathrm{~d}$ in early March, although detectable in February and March. Sardine shoals did not occur in the Kuroshio region, except in early March. It was suggested that sardine were aggregated in inshore regions before spawning and that most of them moved offshore into the Kuroshio region to spawn and returned inshore after spawning
\end{abstract}

\section{INTRODUCTION}

The Japanese sardine Sardinops melanostictus stock began to increase rapidly in the early 1970 s from its low levels during the preceding 3 decades. Annual sardine catches in Japan exceeded 2 million tons in 1980 and were sustained at an extremely high level of 4 million tons from 1984 to 1989 . Recent landings were 3680000 tons in 1990 and 2960000 tons in 1991. The Japanese sardine stock, though at a high abundance, now appears to be entering a period of decline.

Spawning pattern is a fundamental element in understanding fish-stock variability in the context of life-history strategies in which individuals reproduce. Egg and larval surveys have been conducted annually by the National Research Institute of Fisheries Science, Fishery Agency of Japan. These surveys showed that sardine spawning grounds on the Pacific coast of Japan moved as population size increased (Kuroda 1988): in the 1970s when population size increased, the spawning grounds expanded from the area around Kanto, central Japan, to the area around southwestern Japan along the Pacific coast, and in 1980 the spawn- ing grounds were concentrated off southern Kyushu, also extending offshore to the main stream area of the Kuroshio current. In the 1990 s the main spawning grounds tended to return from west to east, but occurrence of eggs was observed in the offshore Kuroshio areas rather than in coastal areas (M. Ishida unpubl.).

To understand the change in spawning grounds may afford an insight into the dynamics of the Japanese sardine population. Despite the extensive egg and larval surveys there is little information on distribution, maturation and spawning of adult Japanese sardine in the spawning season. Hunter \& Goldberg (1980) developed the method for estimating incidence of spawning through histological examination for northern anchovy Engraulis mordax. Postovulatory follicles showing recent spawning were reported for Pacific sardine Sardinops sagax (Goldberg et al. 1984). Our study was prompted by this technique and by the lack of information on the reproductive ecology of the Japanese sardine. The final spawning location and peak spawning period can be determined by measurement of gonadal development and by histological examination of ovaries. 


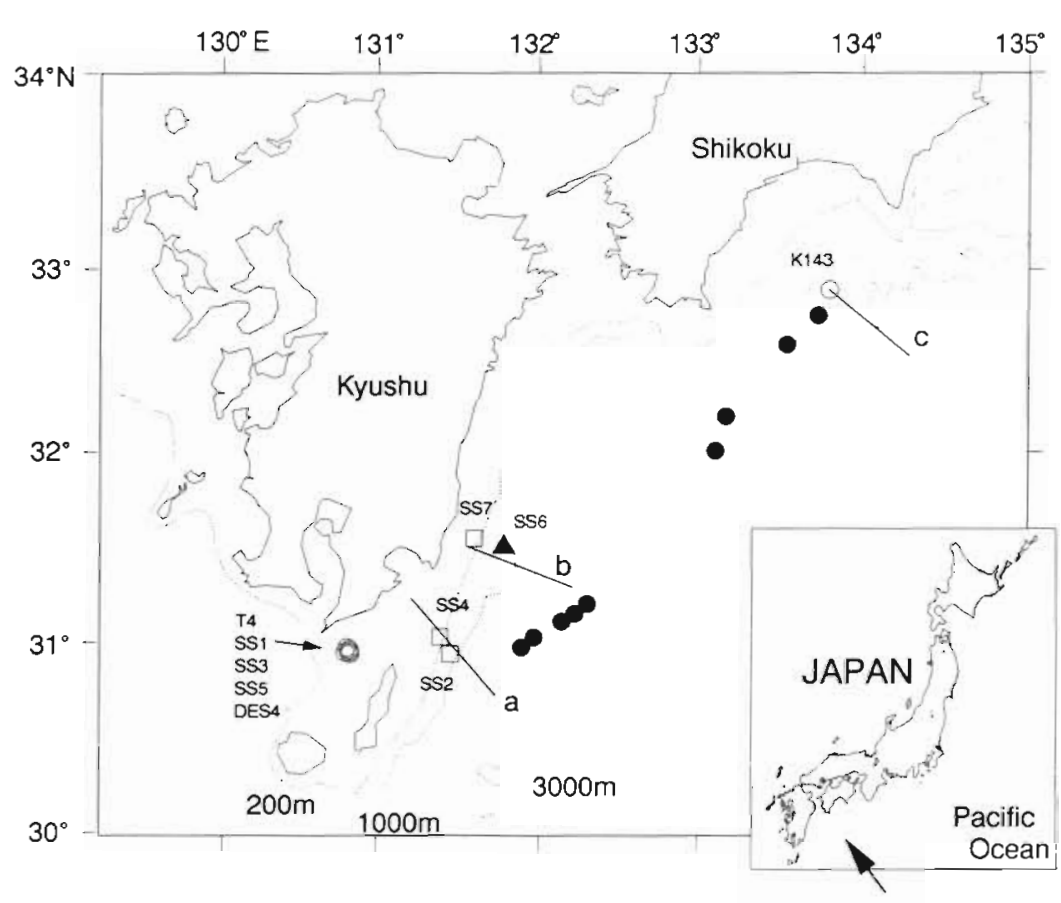

Fig. 1. Sardinops melanostictus. Sampling locatıons of adult Japanese sàrdine off southern Kyushu and Shikoku, southwestern Japan, in January-March 1991. O: coastal region (Stns T4, SS1, SS3, SS5 \& DES4 were at approximately the same location); $\square$ : frontal region; $\Delta$ and $\bullet$ : Kuroshio region ( 9 sampling sites of solid circles were combined as Stn K-a). a, b \& c: transects where vertical section of temperature were measured. Broken lines denote isobaths

\section{MATERIALS AND METHODS}

The sardine spawning season occurs during February and March in the area off southern Kyushu and Shikoku. Two survey cruises of the spawning population were conducted in this region with the RV 'Tansei Maru' from 18 to 28 January 1991 and with the RV 'Hakuho Maru' from 13 February to 22 March 1991. During the 2 survey periods sardine distribution was observed hydroacoustically and sardine samples were collected.

Acoustic observations were made with $50 \mathrm{kHz}$ echo sounders; a Furuno FQ-50 mounted on the RV 'Tansei Maru' and a Furuno FQ-71 on the RV 'Hakuho Maru' Each acoustic system included digital integrators and a personal computer. Transducers were hull-mounted. The systems yielded mean volume back-scattering strengths $(\mathrm{SV}$, in $\mathrm{dB})$ in real time for nine $10 \mathrm{~m}$ depth strata from 10 to $100 \mathrm{~m}$ depth at horizontal integration intervals of 0.2 or $0.4 \mathrm{~nm}$. Acoustic data were analysed with the standard echo integration method (Johannesson \& Mitson 1983).

This paper provides a detailed analysis of the spawning pattern of the Japanese sardine off southern Kyushu and Shikoku, southwestern Japan, in relation to water temperature and the Kuroshio current.
Surface temperature data along tracklines were collected throughout the surveys. CTD and XBT casts were also made to determine oceanographic structure in the survey area.

Table 1. Sardinops melanostictus. Collection data for adult Japanese sardine from off southern Kyushu and Shikoku, southwestern Japan, January-March 1991

\begin{tabular}{|c|c|c|c|c|c|c|c|c|c|}
\hline \multirow[t]{2}{*}{ Region } & \multirow[t]{2}{*}{ Stn } & \multirow{2}{*}{$\begin{array}{l}\text { Collection } \\
\text { method }\end{array}$} & \multirow[t]{2}{*}{ Date } & \multirow{2}{*}{$\begin{array}{l}\text { Local time } \\
\text { (h) }\end{array}$} & \multirow{2}{*}{$\begin{array}{l}\text { Surface temp. } \\
\qquad\left({ }^{\circ} \mathrm{C}\right)\end{array}$} & \multicolumn{2}{|c|}{ Sample size } & \multicolumn{2}{|c|}{ Body length (cm) } \\
\hline & & & & & & $Q$ & $0^{\prime \prime}$ & $९$ & $\sigma^{*}$ \\
\hline \multirow[t]{6}{*}{ Coastal } & $\mathrm{T} 4$ & Gill net & $22-23 \mathrm{Jan}$ & $21: 30-07: 34$ & $18.0-18.3$ & 42 & 23 & $18.9-21.9$ & $18.5-20.7$ \\
\hline & SS1 & Gill net & $20-21 \mathrm{Feb}$ & $22: 40-04: 40$ & $18.0-18.1$ & 95 & 88 & $18.4-22.1$ & $17.5-20.7$ \\
\hline & SS3 & Gill net & $27 \mathrm{Feb}$ & $02: 05-04: 40$ & $17.7-17.8$ & 54 & 57 & $18.0-22.1$ & $17.7-20.6$ \\
\hline & SS5 & Gill net & $9 \mathrm{Mar}$ & $18: 00-20: 25$ & $17.4-17.5$ & 44 & 40 & $18.3-20.8$ & $18.4-21.5$ \\
\hline & DES4 & Angling & $9 \operatorname{Mar}$ & $21: 43-24: 00$ & $17.1-17.5$ & 21 & 7 & $18.1-21.2$ & $17.8-19.4$ \\
\hline & K143 & Angling & $18 \mathrm{Mar}$ & $19: 00-20: 03$ & $17.4-17.5$ & 10 & 17 & $19.3-21.1$ & $17.5-21.1$ \\
\hline \multirow[t]{3}{*}{ Frontal } & SS2 & Angling & 22 Feb & $09: 00-12: 30$ & $19.1-19.4$ & 11 & 6 & $18.7-20.8$ & $18.8-22.4$ \\
\hline & $\mathrm{SS} 4$ & Gill net & 27 Feb & $18: 05-20: 40$ & $18.9-19.0$ & 51 & 52 & $18.3-21.7$ & $17.1-20.5$ \\
\hline & SS7 & Gill net & $11 \mathrm{Mar}$ & $05: 00-06: 45$ & $19.0-19.2$ & 20 & 41 & $19.1-22.2$ & $18.8-21.6$ \\
\hline \multirow[t]{2}{*}{ Kuroshio } & $K-a^{\alpha}$ & Angling & 1-3 Mar & $04: 05-23: 30^{b}$ & $20.5-21.0$ & 50 & 28 & $18.0-21.5$ & $18.1-20.7$ \\
\hline & SS6 & Gill net & $10 \mathrm{Mar}$ & $19: 00-20: 30$ & $21.9-22.0$ & 38 & 30 & $18.7-23.4$ & $18.4-21.1$ \\
\hline
\end{tabular}




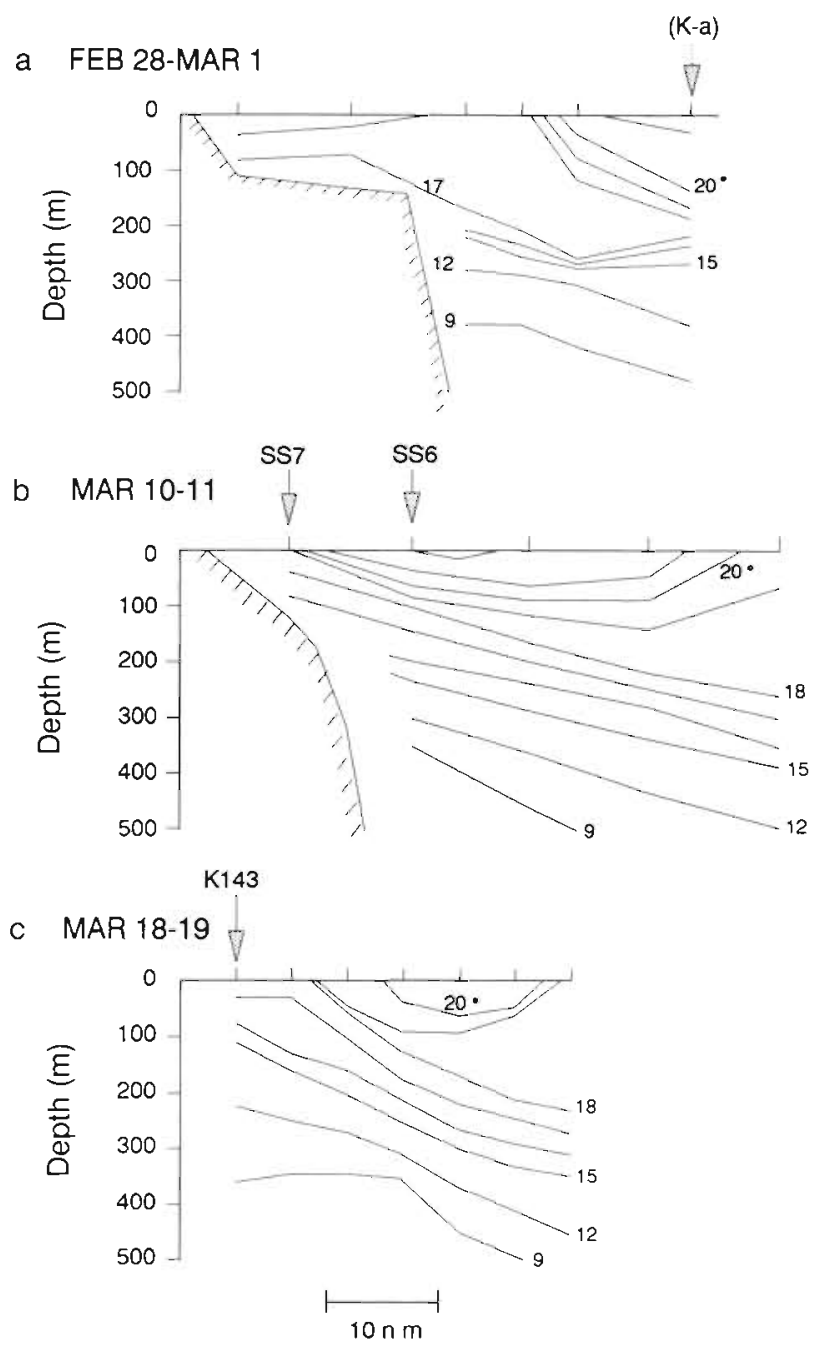

Fig. 2. Sardinops melanostictus. Vertical temperature sections. Locations of transects are given in Fig. 1. The main stream area of the Kuroshio current approximately corresponds to surface temperature $>20^{\circ} \mathrm{C}$. Arrows indicate sampling stations. (a) Stn $\mathrm{K}-\mathrm{a}$ is extrapolated to the transect. When sardine were sampled at Stns SS2 \& SS4 on 22 \& 27 February, the front was located less offshore than in (a)

Sardine were sampled mainly with a gill net and also with fishing lines (Fig. 1, Table 1). A gill net with $43 \mathrm{~mm}$ mesh, $50 \mathrm{~m}$ long and $10 \mathrm{~m}$ high was drifted with its top set at 20 to $30 \mathrm{~m}$ depth. The gill net was used at night and the lines used in both the nighttime and daytime. Sampling stations were classified into 3 oceanographic regions on the basis of surface temperature and relative location to the Kuroshio current (Fig. 2): coastal region, about 17 to $18^{\circ} \mathrm{C}$, nearshore waters far from the Kuroshio current; frontal region, about $19^{\circ} \mathrm{C}$, in the boundary zone of coastal and Kuroshio waters; Kuroshio region, $>20^{\circ} \mathrm{C}$, in the Kuroshio current.

Body cavities of fish sampled were opened immediately on board and gonadal conditions were examined visually. Fish with translucent hydrated eggs just prior to ovulation or running gametes were detected by visual examination of gonads and then recorded. After that, fish were preserved in $10 \%$ neutral buffered formalin. In the laboratory, body length (BL), body weight (BW) and gonad weight (GW) were measured. Then, gonadosomatic index (GSI) was calculated as GSI $=$ GW/BW $\times 100$. For histological examination segments of ovaries were embedded in paraffin and sectioned at a thickness of $8 \mu \mathrm{m}$. The sections were stained with hematoxylin and eosin.

\section{RESULTS}

\section{Distribution of sardine shoals}

In this survey area, many echo-traces of a dense, irregularly shaped layer occurred over a depth range of 10 to $50 \mathrm{~m}$, mostly at 10 to $30 \mathrm{~m}$ depth. Such echotraces were confirmed to be sardine by fishing and using an underwater TV system. Sardine were distributed in the surface mixed layer, where temperature was similar to surface temperature.

For 4 periods between January and March, mean SV for the 10 to $50 \mathrm{~m}$ depth range and the $5 \mathrm{~nm}$ distance interval was calculated and plotted along tracklines (Fig. 3). The mean SV for each $5 \mathrm{~nm}$ block was classified by observing the configuration of echo-traces on echograms: one for the block where echo-traces more probably due to sardine shoals occurred, and the other for the block where only weak diffuse scattering layers due to plankton existed. The former can be representative of fish density. Considering both this distinction and $\mathrm{SV}$ values, it is evident that sardine distribution varied as time advanced. In late January, sardine distribution was confined to the nearshore area along the coast of southern Kyushu where surface temperature was $<19^{\circ} \mathrm{C}$ (Fig. 3a). Sardine also occurred in the coastal waters in mid-February, but fish densities increased and were higher compared with those in late January (Fig. 3b). In contrast, at the end of February and beginning of March, fish densities decreased in the nearshore region and instead high-density areas occurred offshore in the frontal and Kuroshio regions where temperature exceeded $20^{\circ} \mathrm{C}$ (Fig. 3c). Then, in mid-March, most sardine were again concentrated in the coastal waters $<19^{\circ} \mathrm{C}$, while a few shoals were found in the Kuroshio region (Fig. 3d). Subsequent surveys in the same area until 15 March resulted in no encounter with shoals in the Kuroshio region. This change in distribution over time during the spawning season prompted us to examine maturity conditions of sardine occurring in the different waters and periods. 
(a) JAN 20-23

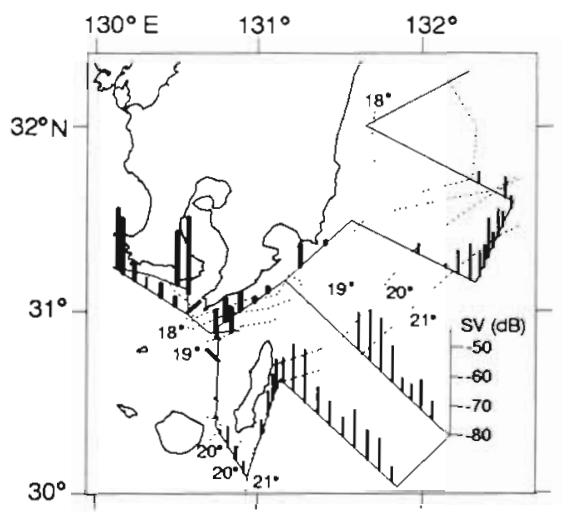

(c) FEB 26-MAR 1

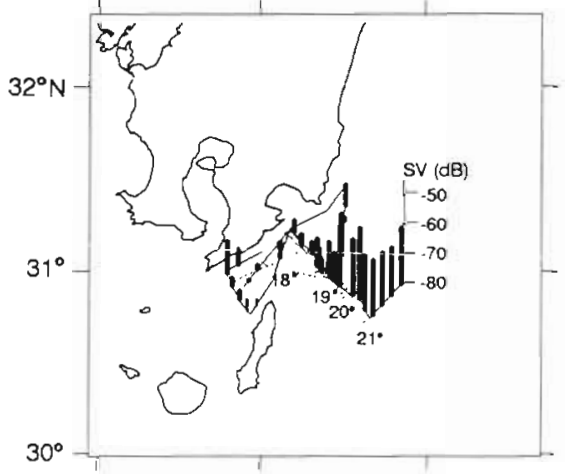

(b) FEB 14-17

\section{FEB 20}

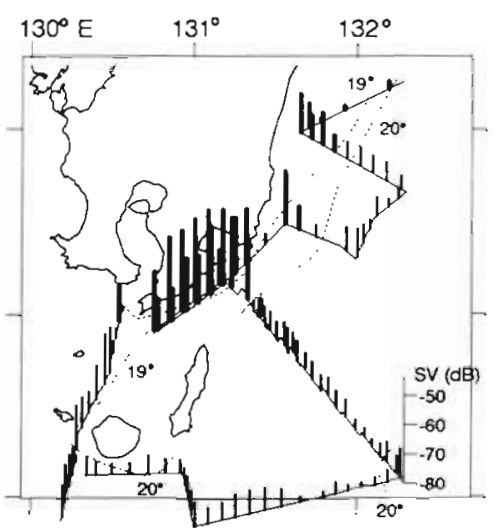

(d) MAR 9-12

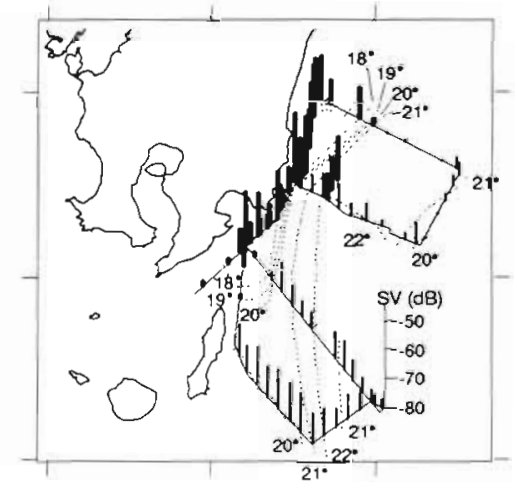

Fig. 3. Sardinops melanostictus. Distribution of integrated echo intensity off southern Kyushu during each of 4 survey periods, January-March 1991. Vertical bars show mean volume scattering strengths (SV) for 10 to $50 \mathrm{~m}$ depth range and $5 \mathrm{~nm}$ distance interval; sardine shoals occurred in the blocks where SV is given by a bold bar. Values below $-80 \mathrm{~dB}$ are not shown. Thin solid lines denote tracklines of the vessel; broken lines indicate surface isotherms in $1{ }^{\circ} \mathrm{C}$ steps

\section{Maturation and spawning}

Ninety-nine percent of the collection of sardine was $>18 \mathrm{~cm} \mathrm{BL}$, which was considered maturity size (Kondo 1988), and only $1 \%$ was between 17 and $18 \mathrm{~cm} \mathrm{BL}$. Therefore, all samples taken in the 2 cruises were analyzed assuming that they could reach sexual maturity.

Frequency distributions of GSI are illustrated for females and males in Figs. 4 \& 5, respectively. The histograms are arranged with the vertical direction showing time progress and the horizontal direction showing oceanographic regions. As shown in Fig. 3 from the echo survey, no shoal was observed in the regions without a histogram. Thus, Figs. $4 \& 5$ provide some illustration of time-space patterns of maturation and spawning of sardine in the spawning season. A similar trend in GSI distribution was observed for both females and males. GSI increased in January and February, showing unimodal distribution as seen for
Stns T4, SS1, SS3 \& SS4. The GSI values in the sample from Stn $\mathrm{K}-\mathrm{a}$ taken on 1 to 3 March in the Kuroshio region showed a wider distribution without a distinct single mode. By 9 to 11 March, GSI exhibited a wide range of values, although GSI values were generally low for females at Stns SS7 \& DES4. About half the females taken in the Kuroshio region (Stn SS6) had translucent hydrated eggs which indicated imminence of spawning. Afterwards, GSI for both sexes from Stn K143 on 18 March were, as a whole, smallest in this survey period, and GSI values of the females were $<5 \%$.

Grading maturity stages from GSI values has ambiguities (Hunter \& Macewicz 1985). The low GSI of postovulatory ovaries could be confused with immature and atretic ovaries (Hunter \& Macewicz $1980,1985)$. Therefore, histological examination was made for 366 females to confirm gonadal conditions estimated from GSI values, which could afford evidence of final maturation and spawning incidence.

Oocytes were observed at various developmental stages from the yolk vesicle stage to the hydrated oocyte stage. Postovulatory follicles ranged from the new ones probably just after ovulation to the relatively degenerating old ones. The migratory nucleus oocytes and translucent hydrated eggs are in the state of final maturation (Matsuura et al. 1991). The former will be spawned in the next 1 or $2 \mathrm{~d}$, and the latter are in the last hours before spawning. The postovulatory follicles are indicative of recent spawning. In recent experiments of hormone-induced spawning of Japanese sardine in the laboratory, by $48 \mathrm{~h}$ after spawning postovulatory follicles were so advanced in degeneration that they could not be readily distinguished from ovarian connective tissue (Shiraishi et al. unpubl.). This rate of degeneration was similar to those of northern anchovy (Hunter \& Goldberg 1980) and Pacific sardine (Goldberg et al. 1984).

The numbers of females with migratory nucleus oocytes, translucent hydrated eggs, postovulatory follicles and atretic oocytes are shown in Table 2, where the sets of numbers for each sampling station 
Fig. 4. Sardinops melanostictus. Frequency distributions of gonadosomatic index (GSI) of adult female Japanese sardine taken off southern Kyushu and Shikoku in JanuaryMarch 1991. Solid columns indicate numbers of females with hydrated eggs. a: coastal region; b: frontal region; c: Kuroshio region

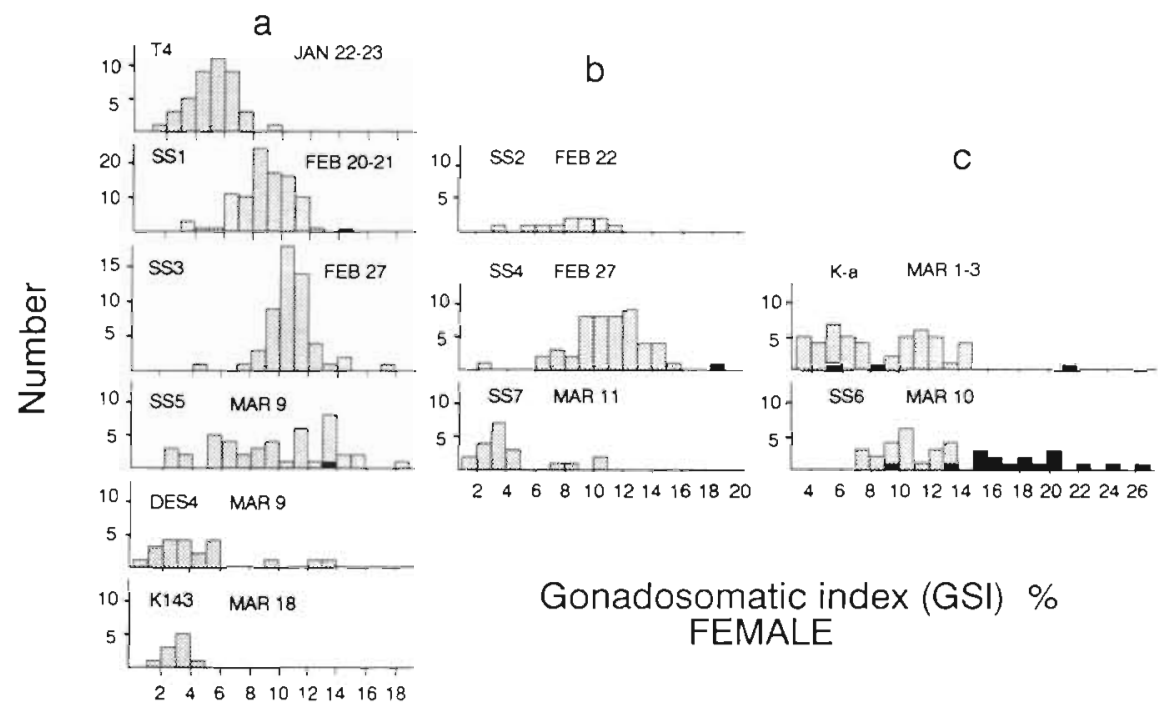

were arranged in the same manner as in Fig. 4. In this study sardine were caught at various times of day. Sampling time may affect occurrence of new postovulatory follicles and translucent hydrated eggs, because Japanese sardine spawn at night between 20:00 and 24:00 h (Nakai et al. 1955). Therefore, it is necessary to consider a combination of females having migratory nucleus oocytes, translucent hydrated eggs and postovulatory follicles. Since these females are at reproductive stages ranging from 1 to $2 \mathrm{~d}$ before spawning to 1 to $2 \mathrm{~d}$ after spawning, the total percentage of these females within each sample can yield a measure of total spawning activity.

Almost all females taken at Stn $\mathrm{T} 4$ in late January were at the developing stage. Most of the females at Stns SS1 \& SS2 in mid-February were at the tertiary yolk globule stage, while only a small portion of females were in the migratory nucleus stage or already spawned. Histological characteristics differed among Stns SS3, SS4 \& K-a in accordance with the differences in GSI distribution. Many new postovulatory follicles occurred in females in the Kuroshio region, showing incidence of spawning. Two females of GSI $<9$ from Stn K-a had both remaining hydrated eggs and postovulatory follicles, being in the act of spawning or immediately after spawning. The wider variation in GSI for Stn K-a implies a compound of nonspawning females and recently spawned females. On the other hand, no females from Stn SS3 taken between 02:05 and $04: 40 \mathrm{~h}$ had postovulatory follicles, though onethird of them were at the migratory nucleus stage similarly to females from Stn K-a. Only a few females taken at Stn SS4 between 18:05 and 20:40 h had migratory nucleus oocytes or translucent hydrated
Fig. 5. Sardinops melanostictus. Frequency distributions of gonadosomatic index (GSI) of adult male Japanese sardine taken off southern Kyushu and Shikoku in JanuaryMarch 1991. a: coastal region; b: frontal region; c: Kuroshio region

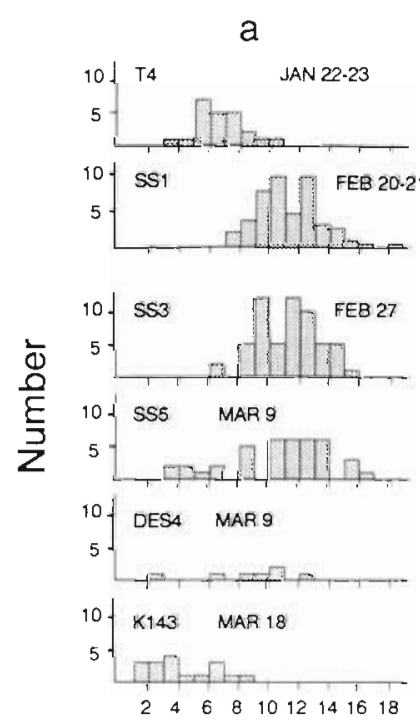

\section{Gonadosomatic index (GSI) \% MALE}


Table 2. Sardinops melanostictus. Numbers of females with migratory nucleus oocytes $(M)$, translucent hydrated eggs $(H)$, postovulatory follicles $(P)$ and atretic oocytes $(A$; more than approximately $1 / 3$ of ovary) for each station ( $\mathrm{n}=$ no. of females histologically examined). Each set of numbers is arranged as in Fig. 4

\begin{tabular}{|c|c|c|c|c|c|c|c|c|c|c|c|c|c|c|}
\hline \multicolumn{5}{|c|}{ a: Coastal region } & \multicolumn{5}{|c|}{ b: Frontal region } & \multicolumn{5}{|c|}{ c: Kuroshio region } \\
\hline$M$ & $H$ & $P$ & $A$ & $\mathrm{n}$ & $M$ & $H$ & $P$ & $A$ & $\mathrm{n}$ & $M$ & $H$ & $P$ & $A$ & $\mathrm{n}$ \\
\hline $\mathrm{T} 4$ & & & & & & & & & & & & & & \\
\hline 2 & 0 & 0 & 0 & 42 & & & & & & & & & & \\
\hline SS1 & & & & & SS2 & & & & & & & & & \\
\hline 9 & 0 & 5 & 2 & 75 & 0 & 0 & 1 & 0 & 11 & & & & & \\
\hline SS3 & & & & & SS4 & & & & & $\mathbf{K}-\mathbf{a}$ & & & & \\
\hline 16 & 0 & 0 & 2 & 45 & 5 & 1 & 0 & 4 & 38 & 14 & 1 & $15^{a}$ & 5 & 50 \\
\hline SS5 & & & & & SS7 & & & & & SS6 & & & & \\
\hline 4 & 1 & 8 & 5 & 30 & 3 & 0 & 16 & 1 & 20 & 4 & 17 & 0 & 1 & 24 \\
\hline DES4 & & & & & & & & & & & & & & \\
\hline 2 & 0 & 1 & 9 & 21 & & & & & & & & & & \\
\hline K143 & & & & & & & & & & & & & & \\
\hline 0 & 0 & 4 & 3 & 10 & & & & & & & & & & \\
\hline
\end{tabular}

eggs. Thus, the total spawning activity, i.e. the total percentage of those females which had migratory nucleus oocytes, translucent hydrated eggs or postovulatory follicles, was significantly higher for females at Stn $\mathrm{K}$-a in the Kuroshio region than for those at Stns SS3 \& SS4 in the coastal and frontal regions (Fig. 6a; $\chi^{2}$-test, $p<0.05$ ).

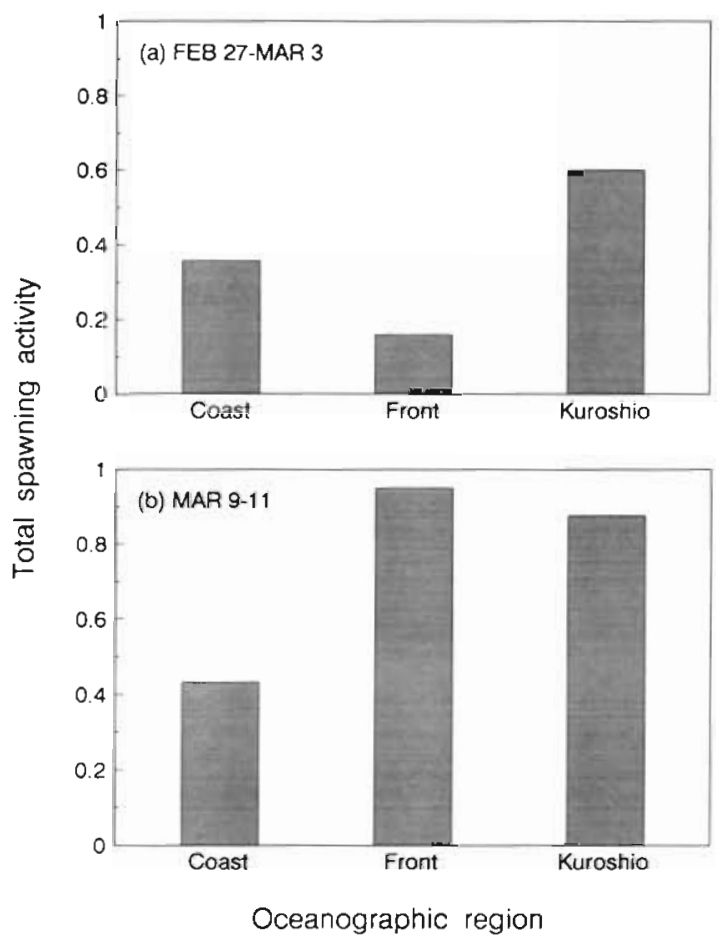

Fig. 6. Sardinops melanostictus. Total spawning activity of adult female Japanese sardine in the 3 oceanographic regions during peak spawning period
Later, more than half the females from Stn SS7 in the frontal region had postovulatory follicles and many females from Stn SS6 in the Kuroshio region had translucent hydrated eggs. The difference in oocyte maturity between the samples from Stns SS6 \& SS7 was due to the sampling time. In any case, total spawning activity was higher in these samples than in the sample from Stn SS5 in the coastal region (Fig. 6b; $x^{2}$-test, $\left.\mathrm{p}<0.05\right)$.

In mid-March sardine shoals were found only in inshore areas. Results of histological examination for females at Stn K143 showed low spawning activity. The sardine in this study area were probably at the early post-spawning stage.

In conclusion, maturity data indicated that spawning activity was higher in the Kuroshio region than in the inshore region, and that it was intermediate in the frontal region. In addition, it is probable that peak spawning was in a short period of about $10 \mathrm{~d}$ in early March.

\section{DISCUSSION}

Sardine shoals were distributed in the coastal and Kuroshio regions, but the maturity data showed a difference in spawning activity between the regions. Sardine in the process of spawning were found more frequently in the Kuroshio region during the short period in early March. Excepting this period sardine shoals did not occur in the Kuroshio region. The distribution and reproductive states in early March in this survey are similar to those in the previous survey from 3 to 9 March 1990 (Aoki \& Murayama 1991). The results of GSI analysis and ovarian histology are con- 
firmed by egg surveys from this cruise in February and March. Densities of sardine eggs in the coastal region were 2 orders of magnitude lower compared with those in the Kuroshio region, and moreover most of the eggs taken in the coastal region were at the later developmental stage (Nakata unpubl.). This is consistent with our results. Although the number of our collections of adult sardine seems too low to allow definitive conclusion, we feel confident that the spawning patterns reported in this study are reasonable approximations to reality. Sardine spawning was closely associated with the Kuroshio current. It is plausible that sardine were aggregated in inshore regions before spawning and that most of them moved offshore into the Kuroshio to spawn and returned inshore after spawning.

Females with low GSI values may be oversampled by angling. The proportion of females with low GSI values were higher in samples caught by angling at Stns K-a, DES4 \& K143 than in samples caught by gill net in the same region or the same period, while mean values of GSI were not different between Stns SS1 (gill net) \& SS2 (angling). Among female samples caught by angling, however, the sample from Stn $\mathrm{K}$-a in the Kuroshio region contained females with relatively high GSI values compared with samples from Stns DES4 \& $\mathrm{K} 143$ in the coastal region. In addition, histological examination showed higher spawning activity in females at Stn K-a than in females at Stns DES4, K143 \& SS2.

Around 1950, when stock levels were low, Japanese sardine spawned inshore on the continental shelf (Nakai et al. 1955). When spawning grounds began to occur in the area south of Kyushu in 1976, they were still in the coastal region (Konishi 1983). It seems that Japanese sardine changed their spawning habits from inshore to offshore spawning in the Kuroshio region for reproduction to be successful in response to increased population size in the 1980s. Sharp (1980) pointed out that placing eggs into an appropriate environment is the life's work of fish. It has been shown that Californian sardine Sardinops sagax and Brazilian sardine Sardinella aurita spawn in coastal bights so as to aid retention of drifting reproductive products within the bights (Parrish et al. 1981, Bakun \& Parrish 1990). Japanese sardine in high abundance, however, do not apply this strategy. The shift of spawning grounds inside the Kuroshio current and to upstream regions of the Kuroshio current may lead to intensifying geographical dispersal of pelagic eggs and larvae of sardine. Economou (1991) proposed a hypothesis that dispersal of eggs and larvae has a significance in reducing intraspecific competition, also involving a trade-off between competition and unfavourable transport. Considering the change in the main spawn- ing grounds associated with population size, the reproductive strategy of Japanese sardine seems to obey Economou's (1991) hypothesis. It has been reported that sardine larvae were widely distributed in the Kuroshio Extension in the north Pacific, though their densities were low (Kuroda 1989).

On the other hand, dispersal costs must be taken into account. Recent year-class abundance abruptly declined to a low level. It can be considered that the balance between costs and benefits of dispersal in the past has been lost. To identify the factors controlling the success or failure of recruitment is the greatest problem.

The change in the spawning grounds involved an increase in water temperature of the spawning areas. Water temperature is higher in the area off southwestern Japan, and it is still higher in the Kuroshio current. Temperature in the spawning areas of Japanese sardine ranged from 11 to $19^{\circ} \mathrm{C}$, mostly between 13 and $16^{\circ} \mathrm{C}$ around 1950 (Nakai et al. 1955). In our survey area, spawning sardine occurred where temperature exceeded $20^{\circ} \mathrm{C}$. In Japanese sardine, egg hatching takes 3 to $3.5 \mathrm{~d}$ at $15^{\circ} \mathrm{C}$ and about $1.5 \mathrm{~d}$ at $20^{\circ} \mathrm{C}$ (Nakai 1962). Kuroda et al. (1985) suggested that the Kuroshio front and Kuroshio region in winter was a good environment for biological production because of convectional mixing and high temperature. High temperature can play a part in reducing dispersal costs involved in long drift, by lessening incubation time and promoting growth. It is likely to be advantageous for pelagic fish to grow as fast as possible (Lambert \& Ware 1984).

It is remarkable that spawning was concentrated within a short period of about $10 \mathrm{~d}$, though detectable in February and March. Lambert \& Ware (1984) suggest that pelagic spawners such as Atlantic mackerel and white hake apply reproductive tactics wherein eggs are released over a short period and hatch into fast-growing larvae. Growth rates of Japanese sardine reared in the laboratory were $0.67 \mathrm{~mm} \mathrm{~d}^{-1}$ for $15 \mathrm{~d}$ (Hayashi et al. 1989) and about $1 \mathrm{~mm} \mathrm{~d}^{-1}$ for $80 \mathrm{~d}$ (Nakamura et al. 1991). Using daily increments on the otoliths, a growth rate of $0.7 \mathrm{~mm} \mathrm{~d}^{-1}$ has been obtained for field-caught larvae of 11 to $29 \mathrm{~mm}$ length (Kuroda 1991). These growth rates show that Japanese sardine larvae belong to the fast-growing group in clupeoid fishes (Blaxter \& Hunter 1982). Lambert \& Ware's (1984) suggestion seems appropriate for explaining the short period of peak spawning of the Japanese sardine.

Although Japanese sardine is believed to be a batchspawner, frequency or cycle of spawning and the number of spawnings per year remain ambiguous. Nakai (1962) considered from distributions of egg diameter according to Clark (1934) that sardine may spawn 2 or 3 times in a season. By examining egg dia- 
meter composition, Usami (1964) inferred that sardine may spawn once in a season at least in a particular spawning area. Sardine hormone-induced in the laboratory spawned at an interval of about $6 \mathrm{~d}$ (Shiraishi et al. unpubl.). Assuming this interval, the sardine may have spawned once or at most twice in this area. Reliable estimates of the frequency and number of spawnings are necessary not only to understand the reproductive strategy of the Japanese sardine but also for stock assessment by egg production.

Fish make tactical changes in reproductive strategy in response to variable environment (Wootton 1984). This work needs to be continued in order to follow changes in the reproductive characteristics of the Japanese sardine. We are concerned about how the changes will take place in another declining phase of sardine stock abundance.

Acknowledgements. We are grateful to Dr Tadashi Inagaki of the Ocean Research Institute, University of Tokyo, who assisted in acquisition of acoustic data. We thank Dr Manabu Shiraishi of the National Research Institute of Aquaculture, Dr Hideaki Nakata of the Ocean Research Institute, and Mr Minoru Ishida of the Nansei National Research Institute of Fisheries Science, for providing unpublished data. Mr Nobuyuki Azuma of the Ocean Research Institute assisted in the measurement of GSI. Thanks are also due to the officers and crew of the RV 'Tansei Maru' and RV 'Hakuho Maru' of the Ocean Research Institute for their help and support

\section{LITERATURE CITEDD}

Aoki, I., Murayama, T (1991). Distribution and maturation of the spawning sardine, Sardinops melanostictus in the waters off southern Kyushu of Japan. Bull. Jap. Soc. Fish. Oceanogr. 55: 93-104

Bakun, A., Parrish, R. H. (1990). Comparative studies of coastal pelagic fish reproductive habitats: the Brazilian sardine (Sardinell aurita). J. Cons. int. Explor. Mer 46: $269-283$

Blaxter, J. H. S., Hunter, J. R. (1982). The biology of the clupeoid fishes. Adv. mar. Biol. 20: 1-223

Clark, F. N. (1934). Maturity of the California sardine (Sardina caerulea) determined by ova measurements. Calif. Fish Game Fish. Bull. 42: 1-49

Economou, A. N. (1991). Is dispersal of eggs, embryos and larvae an insurance against density dependence? Environ. Biol. Fish. 31: 313-321

Goldberg, S. R., Alarcon, V. H. Alheit, J (1984). Postovulatory follicle histology of the Pacific sardine, Sardinops sagax, from Peru. Fish. Bull. U.S. 82: 443-445

Hayashi, A., Yamashita, Y., Kawaguchi, K., Ishii, T (1989). Rearing method and daily otolith ring of Japanese sardine larvae. Nippon Suisan Gakk. 55: $997-1000$

Hunter, J. R., Goldberg, S. R. (1980). Spawning incidence and batch fecundity in northern anchovy, Engraulis mordax. Fish. Bull. U.S. 77: 641-652

Hunter, J. R., Macewicz, B. J (1980). Sexual maturity, batch fecundity, spawning frequency, and temporal pattern of spawning for the northern anchovy, Engraulis mordax, during the 1979 spawning season. CalCOFI Rep. 21. 139-149

Hunter, J. R., Macewicz, B. J. (1985). Measurement of spawn- ing frequency in multiple spawning fishes. In: Lasker, $R$ (ed.) An egg production method for estimating spawning biomass of pelagic fish: application to the northern anchovy, Engraulis mordax. NOAA. Tech. Rep. NNFS 36 , p. $79-94$

Johannesson, K. A., Mitson, R. B. (1983). Fisheries acoustics: a practical manual for aquatic biomass estimation. FAO Fish, tech. Pap. 240: 1-249

Kondo, K. (1988). On the mode of distribution and migration of the Japanese sardine, Sardinops melanostictus at high level stock size. Bull. Tokai reg. Fish. Res. Lab. 124: 1-33

Konishi, Y. (1983). Distribution of eggs and larvae of sardine in the Satsunan area, 1976-1981. Bull. Nansei reg. Fish. Res. Lab. 15: 103-121

Kuroda, K. (1988). Yearly changes of the main spawning grounds of the sardine, Sardinops melanostictus (T. et S.) in the waters along the Pacific coast of southern Japan. Bull. Japan. Soc. Fish. Oceanogr. 52: 289-296

Kuroda, K. (1989). Distribution of the Japanese sardine larvae, Sardinops melanostictus (T. et S.) in the Kuroshio area off the Pacific coast of southern Japan to the Kuroshio Extension area during February to April 1986. Bull. Jap. Soc. Fish. Oceanogr. 53: 458-461

Kuroda, K. (1991). Studies on the recruitment process focusing on the early life history of the Japanese sardine, Sardinops melanostictus (Schlegel). Bull. natn. Res. Inst. Fish. Sci. 3: 25-278

Kuroda, K., Kidachi, T., Tomosada, A., Segawa, K. (1985). A case study on small-scale structure of the Kuroshio front and microdistribution of plankton in the sea south of Cape Shionomisaki, Japan. Bull. Tokai reg. Fish. Res. Lab. 115: $47-64$

Lambert, T. C., Ware, D. M. (1984). Reproductive strategies of demersal and pelagic spawning fish. Can. J. Fish. Aquat. Sci. 41: 1565-1569

Matsuura, S., Matsuyama, M., Otsuka, T., Takeshita, K. Mitani, T., Ogawa, N. (1991). Histological maturity scales, maturation and spawning in Kyushu-subpopulation sardine, Sardinops melanostictus. In: Kawasaki, T. Tanaka, S., Toba, Y., Taniguchi, A. (eds.) Long-term variability of pelagic fish populations and their environment. Pergamon Press, Oxford, p. 221-228

Nakai, Z. (1962). Studies relevant to mechanisms underlying the fluctuation in the catch of the Japanese sardine, Sardinops melanosticta (Temminck \& Schlegel). Jap. J. Ichthyol. 9: 1-115

Nakai, Z., Usami, S., Hattori, S., Honjo, Y., Hayashi, S. (1955). Progress report of the cooperative iwashi resources investigations. Tokai reg. Fish. Res. Lab., Tokyo

Nakamura, M., Takii, K., Takaoka, O., Furuta, S., Kumai, H. (1991). Rearing of Japanese sardine from hatching through juveniles. Nippon Suisan Gakk. 57: 345

Parrish, R. H., Nelson, C. S., Bakun, A. (1981). Transport mechanisms and reproductive success of fishes in the California Current. Biol. Oceanogr. 1: 175-203

Sharp, G. D. (1980). Report of the workshop on effects of environmental variation on survival of larval pelagic fishes. IOC Workshop Report 28: 15-63

Usami, S. (1964). Fecundity of the Japanese sardine, Sardinops melanosticta (Temminck \& Schlegel). I. Process of maturation and the number of ova determined on the basis of ovum diameter measurement of the large-sized females taken from the Japan Sea. Bull. Tokai reg. Fish. Res. Lab. 38: 1-30

Wootton, R. J. (1984). Introduction: strategies and tactics in fish reproduction. In: Potts, G. W., Wootton, R. J. (eds.) Fish reproduction: strategies and tactıcs. Academic Press, London, p. 1-12 